\title{
ФОРМИРОВАНИЕ КУЛЬТУРЫ САМОСТОЯТЕЛЬНОЙ РАБОТЫ СТУДЕНТОВ ТЕХНИКУМА: МОДЕЛИ И ВОЗМОЖНОСТИ
}

\author{
Коновалов С.В. ${ }^{1,2}$, Бойкова И.В. ${ }^{3}$, Козырева О.А. ${ }^{4}$ \\ ${ }^{1}$ Самарский национальный исследовательский университет имени академика С.П. Королева, Самара, е-таіl: \\ ksv@ssau.ru; \\ ${ }^{2}$ Уханьский текстильный университет, Ухань; \\ ${ }^{3}$ Новокузнецчкий институт филиал ФГБОУ ВО «Кемеровский государственный университет», Новокузнеияк, е- \\ mail:bkv-iv@yandex.ru; \\ ${ }^{4}$ Сибирский государственный индустриальный университет, Новокузнеик, е-таil: kozireva-оa@yandex.ru \\ В статье определены особенности постановки и решения задач формирования культуры \\ самостоятельной работы студента техникума, в структуре данной реализуемой в исследовании практики \\ уточнены понятия «самостоятельная работа студента техникума» (широкий, узкий, локальный, \\ персонифицированный, здоровьесберегающий, гуманистический и унифицированный смыслы), процесс \\ формирования культуры самостоятельной работы студента техникума, технология формирования \\ культуры самостоятельной работы студента техникума, педагогические условия формирования \\ культуры самостоятельной работы студента техникума, уточнены унифицированные педагогические \\ условия формирования культуры самостоятельной работы студентов техникума. Повышение качества \\ решения задач развития в модели непрерывного образования непосредственно связано с возможностями \\ сформированности и результативностью формирования культуры самостоятельной работы личности \\ студента техникума. На ступени среднего профессионального образования (техникум) формирование \\ культуры самостоятельной работы студента техникума определяется через уровневое решение задач \\ развития и самореализации личности в учебной, профессионально-трудовой и здоровьесберегающей \\ системах проектирования результатов деятельности личности и общества. Все выделенные модели и \\ механизмы формирования культуры самостоятельной работы студентов техникума определяют на \\ различных уровнях потенциальные и реализуемые условия развития личности студентов техникума, \\ определяют качество решения задач самореализации и сотрудничества.
}

Ключевые слова: культура самостоятельной работы студента техникума, моделирование, модель, технология формирования культуры самостоятельной работы студента техникума.

\section{FORMATION OF THE CULTURE OF THE SELF-WORKING STUDY OF THE TRAINING TECHNICUM: MODELS AND OPPORTUNITIES}

\author{
Konovalov S.V. ${ }^{1,2}$, Boykova I.V. ${ }^{3}$, Kozyreva O.A. ${ }^{4}$ \\ ${ }^{1}$ Samara National Research University, Samara, e-mail: ksv@ssau.ru; \\ ${ }^{2}$ Wuhan Textile University, Wuhan; \\ ${ }^{3}$ Novokuznetsk Branch-Institute of Kemerovo State University, Novokuznetsk, e-mail: bkv-iv@yandex.ru; \\ ${ }^{4}$ Siberian State Industrial University, Novokuznetsk, e-mail: kozireva-oa@yandex.ru
}

The article defines the features of the formulation and solution of problems of formation of culture of selfdependent work of a student of a technical school, in the structure of this practice implemented in the study, the concepts of " self-dependent work of a student of a technical school" (wide, narrow, local, personalized, healthsaving, humanistic and unified meanings), the process of formation of culture of self-dependent work of a student of a technical school, the technology of formation of culture of self-dependent work of a student of a technical school, pedagogical conditions of formation of culture of self-dependent work of a student of a technical school, the unified pedagogical conditions of formation of culture of self-dependent work of students of technical school are specified. Improving the quality of solving the problems of development in the model of continuous education is directly related to the possibilities of formation and effectiveness of the formation of a culture of self-dependent work of the individual student College. At the stage of secondary vocational education (College), the formation of a culture of self-dependent work of a College student is determined through the level solution of the problems of development and self-realization of the individual in the educational, professional and healthsaving systems of designing the results of the individual and society. All selected models and mechanisms of formation of culture of self-dependent work of students of technical school determine at various levels the potential and realizable conditions of development of the personality of students of technical school, define quality of the solution of problems of self-realization and cooperation.

Keywords: culture of self-dependent work of a student of a technical school, modeling, model, technology of formation of culture of self-dependent work of a student of a technical school. 
Самостоятельная работа студента техникума и формирование культуры самостоятельной работы студента техникума определяют устойчивые связи развития личности в моделях продуктивности, персонификации, конкурентоспособности. Качество решения задач развития и саморазвития личности представляет функцию и ресурс продуктивного выбора персонифицированных решений задачи «хочу, могу, надо, есть», располагающих личность и общество к ситуативному уточнению оптимальной возможности создания нового знания или новых продуктов в социально-образовательной и/или профессионально-трудовой среде.

Успешность поиска оптимальных решений задач формирования культуры самостоятельной работы студента техникума в иерархии детерминируемых и решаемых задач будет опираться на следующие теоретико-эмпирические положения общей и профессиональной педагогики: теоретико-эмпирические основы продуктивного решения задач включения личности в систему научно-педагогического поиска и успешность решения задач формирования культуры деятельности (самостоятельной работы) позволят уточнить особенности решений задач детерминации и оптимизации педагогической деятельности как категории педагогики и еe составных конструктов, определяющих в культуре самостоятельной работы студента техникума возможность продуктивного становления и самоутверждения, самореализации и социализации [1]; специфика организации продуктивной самостоятельной работы студентов [2] в изучении проблем и возможностей конструктивной педагогики позволит качественно решать уровневые задачи научного поиска и уточнять понятийный аппарат педагогики, в качестве примера будут выбраны понятия «самостоятельная работа студента техникума», «культура самостоятельной работы студента техникума»; основы педагогического моделирования в конструктах современного образования [3] определят результативность уточнения понятийного аппарата современной педагогической науки; сущность профессиональной деятельности специалистов социальной работы на современном этапе развития общества [4] определит специфику детализации педагогических условий решения поставленной в работе научно-педагогической задачи; формирование профессиональных качеств педагога [5] определяет качество формирования и сформированности детерминируемых показателей и составных продуктивного становления личности студента техникума; адаптивная составляющая профессиональной мобильности [6] определит в структуре формирования культуры самостоятельной работы студента техникума возможность учета условий нормального распределения способностей и здоровья в учебной группе; информационные технологии в организации самостоятельной работы студентов и педагогов $[7 ; 8]$ определят перспективность инновационного развития личности в культуре здоровья, культуре деятельности, культуре самостоятельной работы личности; 
педагогическая деятельность [9-11] позволит выделить составным условием продуктивное решение задачи формирования культуры самостоятельной работы студента техникума в плоскости реализации парадигмы гуманистического образования; процесс организации самостоятельной работы студентов в условиях информатизации вузов [12] определит одним из видов реализации продуктивного развития личности студента самостоятельную работу с использованием информационных ресурсов современного воспитательно-образовательного пространства, подготовив личность к различным условиям развития поставленной в деятельности задачи и детализируемых в ведущей деятельности и общения противоречий и проблем; научное исследование [13] определит все составные оптимизации и детализации педагогических условий формирования культуры самостоятельной работы студента техникума; непрерывное развитие профессиональной компетентности преподавателя и организация самостоятельной работы студентов [14; 15] определят качество решения задач в модели современного образования и профессионально-трудовых отношений; современные педагогические технологии, в том числе и интерактивные технологии в формировании познавательной самостоятельности студентов [16], могут быть использованы в структуре уровневого развития и становления личности студента, определяя в моделях и механизмах формирования культуры самостоятельной работы студентов техникума возможность персонификации и унификации решаемой в работе задачи; педагогический процесс как категория и конструкт современной педагогической деятельности определяет успешность постановки и решения задач современной педагогической методологии, раскрывающей особенности процессуального подхода [17] как способа оптимизации качества научного поиска в среднем профессиональном образовании; возможность использования адаптивного обучения [18] на уровне моделей и механизмов формирования культуры самостоятельной работы студентов техникума повышает качество и возможность персонификации и унификации развития личности; организация самостоятельной работы с использованием современных средств электронного обучения и дистанционного обучения $[19 ; 20]$ определяет перспективность деятельности педагога в определении и решении задач формирования культуры самостоятельной работы студентов техникума.

Цель исследования: изучение и уточнение возможностей формирования культуры самостоятельной работы студентов техникума, фасилитирующих понимание целостности и уникальности развития личности в системе среднего профессионального образования, обеспечивающего включенность личности в систему профессионально-трудовых отношений и современного непрерывного образования в мировом образовательном пространстве. 
Самостоятельная работа студента техникума как категория профессиональной педагогики может быть уточнена в широком, узком, локальном, персонифицированном, здоровьесберегающем, гуманистическом и унифицированном смыслах.

Самостоятельная работа студента техникума (широкий смысл) - способ и форма решения учебно-познавательных, учебно-производственных и профессионально-трудовых задач в модели современного профессионального образования, условия и специфика которых на современном этапе в системе среднего профессионального образования реализуется через группу компетенций ФГОС СПО, условно определяемых в конструктах «ОК - общая компетенция», «ПК - профессиональная компетенция», в единстве гарантирующих высокие результаты деятельности обучающихся, качество включенности обучающегося в систему профессионально-трудовых отношений и персонифицированное решение задачи развития и саморазвития, самореализации и социализации личности через систему непрерывного образования и профессионально-трудовой деятельности.

Самостоятельная работа студента техникума (узкий смысл) - процесс формирования активности личности в выборе методов и средств решения учебных, учебно-познавательных, учебно-производственных, учебно-тренировочных и профессионально-трудовых задач, гарантирующих в выполнении высокие результаты самоутверждения и самореализации, визуализируемые через социально и конкурентно востребованные продукты ведущей деятельности личности, получающей образование в системе СПО.

Самостоятельная работа студента техникума (локальный смысл) - процедура выполнения обучающимся (студентом) техникума ситуативной задачи или ситуативно выделенного противоречия, непосредственно связанных с учебно-образовательной деятельностью в образовательном учреждении системы СПО.

Самостоятельная работа студента техникума (персонифицированный смысл) - модель развития и саморазвития личности, уточнение особенностей и возможностей которой определяется ситуативностью решения задач «хочу, могу, надо, есть», способностью педагога качественно определить нюансы оказания педагогической поддержки личности, педагогической помощи и фасилитации изучаемого дидактического материала.

Самостоятельная работа студента техникума (здоровьесберегающий смысл) - продукт самоорганизации качества развития и саморазвития личности в структуре учебнообразовательной подготовки студента техникума, определяющего через здоровый образ жизни и культуру здоровья возможность продуктивного персонифицированного становления и самоутверждения, самореализации и социализации, сотрудничества и общения, гарантирующих в единстве повышение качества жизни личности и общества в целом. 
Самостоятельная работа студента техникума (гуманистический смысл) - механизм оптимизации качества развития студента техникума в модели организуемой педагогами деятельности, стимулирующей студента техникума к высоким персонифицированным результатам становления и самоутверждения, сотрудничества и самовыражения, раскрывающим перспективы личности и общества в различных масштабах (микро-, мезо-, макро-, мега-, уни-, комбо- и пр.) и моделях развития и деятельности личности и коллектива.

Самостоятельная работа студента техникума (унифицированный смысл) - форма и технология организации работы с обучающимися техникума, гарантирующая персонифицированную проверку качества формирования компетенций у обучающегося в структуре изучаемого предмета (дисциплины), определяющего перспективность профессионального становления личности как продукта эволюции непрерывного образования и развития ноосферного выбора личностью условий и продуктов самоорганизации и самосохранения.

Процесс формирования культуры самостоятельной работы студента техникума поэтапное развитие личности студента техникума в решении уровневых задач становления и самоутверждения, самореализации и самосохранения, в модели которых продуктивность и креативность, здоровьесбережение и гибкость определяют качество и уровень достижений и уровень развития личности в структуре получаемого в техникуме образования, основы и качество которого регламентируют ФГОС и персонификация деятельности студента техникума.

Методы формирования культуры самостоятельной работы студента техникума - пути и способы традиционной и инновационной педагогики, определяющие возможности продуктивного становления личности через поэтапное персонифицированное решение задач акмедостижений студента техникума в модели получаемого образования и образовательных услуг.

Технология формирования культуры самостоятельной работы студента техникума адаптивно-акмепедагогический способ оптимизации качества решения задач развития студента техникума в структуре реализации ФГОС СПО, определяет возможность постановки цели, выбора средств и методов формирования культуры самостоятельной работы студента техникума, гарантирующих определенный уровень или продукт новообразований в развитии личности студента техникума и качества обеспечения получаемого образования и будущих профессионально-трудовых отношений.

Педагогические условия формирования культуры самостоятельной работы студента техникума - совокупность основополагающих и конкретизирующих оптимальный выбор положений, детерминирующих и фасилитирующих качественное решение задач развития 
обучающегося в персонифицированном поиске оптимальных общепедагогических, профессионально-педагогических и частно-предметных конструктов самоорганизации деятельности и общения, определяемых нами через общеучебные и предметные знания, умения, навыки и компетенции.

Выделим унифицированные педагогические условия формирования культуры самостоятельной работы студентов техникума:

1. Разработка программно-педагогического обеспечения и адаптивноакмепедагогической поддержки изучения курсов современной науки в соответствии с ФГОС СПО определит уровневую модель решения задач развития личности через признание продуктивной деятельности личности студента техникума высшим эталоном, определяющим возможности (модели и пр.) развития личности в системе самосовершенствования и самореализации.

2. Создание условий для объективного определения уровня профессиональной подготовки и реализации возможностей продуктивной деятельности $\mathrm{B}$ структуре прохождения производственных практик, последовательно и системно верифицирующих качество усвоения теоретического материала.

3. Стимулирование активности выбора обучающихся (студентов техникума) в условиях непрерывного профессионального образования в модели самореализации и самосовершенствования, где стимулирование производится различными механизмами формирования мотивации труда и обучения.

4. Учет потребностей и возможностей студентов техникума, включенных в условия непрерывного профессионального образования, и социума в специалистах того или иного уровня / категории, определяющих задачу «хочу, могу, надо, есть» базовой функцией самоорганизации развития и самоутверждения личности.

5. Определение и оптимизация возможностей использования технологий формирования культуры самостоятельной работы студента техникума в системе профессионального образования, в структуре которых происходят общие, частные и частноспециальные изменения, данная практика зависит от качества и уровня включения личности в систему продуцирования изобретений и инноваций, определяющих в области подготовки специалистов различного уровня и класса конструкты и модели компетенций, детерминированных и детализированных в структуре реализации ФГОС СПО.

6. Формирование потребности у образовательных учреждений общего образования реализовывать программы определенной направленности или профильной подготовки (технической, гуманитарной и пр.), системно и качественно формирующие основы математических знаний, естественно-научных и технических дисциплин, определяющие в 
условиях соблюдения и принятия основ нормального распределения способностей обучающихся средние значения отправными величинами, от которых следует отталкиваться в определении и решении задач развития современного образования.

7. Принятие основ дидактического обеспечения в ресурсах целостности и непрерывности, системности и последовательности, систематичности и объективности необходимым звеном развития личности и системы профессионального образования.

8. Востребованность продуктов научного, научно-методического, научнопедагогического и научно-технического творчества обучающихся (студентов техникума) в системе функционирования государственно-региональных институтов.

9. Реализация персонифицированных, объективных и практико-ориентированных условий повышения конкурентоспособности личности студента техникума и государственно-региональных институтов труда и производства, определяющих потребность в повышении качества создаваемых объектов и продуктов научно-педагогического и научнотехнического творчества - основными механизмами устойчивости развития и сохранения научного потенциала нации и государства.

10. Формирование потребности у педагогов и студентов техникума в разностороннем знании и культуре общения и взаимодействия.

Повышение качества решения задач развития в модели непрерывного образования непосредственно связано с возможностями сформированности и результативностью формирования культуры самостоятельной работы личности.

На ступени среднего профессионального образования (техникум) формирование культуры самостоятельной работы студента техникума определяется через уровневое решение задач развития и самореализации личности в учебной, профессионально-трудовой и здоровьесберегающей системах проектирования результатов деятельности личности.

Эффективность формирования культуры самостоятельной работы студентов техникума определяется в качестве определяемых и решаемых задач, детерминация основ и способов, методов и условий которых определена структурой и содержанием современного образования, в нашей ситуации - это система среднего профессионального образования, где ФГОС СПО выделяет и решает в конструктах компетентностного и функциональнотрудового подходов оптимальные ресурсы и формы, технологии и условия повышения качества решения задач развития личности, предопределяющего продуктивную социализацию личности, конкурентоспособные отношения, продуктивноперсонифицированное становление личности с учетом особенностей развития и практики продуктивного самоутверждения, сотрудничества и общения. 
Эффективность технологии формирования культуры самостоятельной работы студентов техникума может быть определена через общее, частно-предметное и частноспециальное решение той или иной задачи:

- использование программно-педагогического сопровождения, определяющего качество обучения в общем и частно-предметном ракурсах описания и визуализации достижений личности;

- использование метода проектов в решении задач акмеперсонификации качества развития личности и включенности личности обучающегося в систему социальнообразовательных и профессионально-трудовых отношений;

- выполнение курсовых работ и курсовых проектов на высоком уровне качества решения профессионально-трудовых задач;

- участие в заочной Международной научно-практической конференции обучающихся «Портфолио как итог формирования культуры самостоятельной работы обучающегося»;

- участие студентов техникумов в очно организуемых международных, всероссийских и региональных научно-практических конференциях и пр.

Данная практика определяет успешность постановки и решения задач персонификации развития личности в системном выборе оптимальной модели и механизмов формирования культуры самостоятельной работы студентов техникума (игровой, адаптивной, рефлексивно-деятельностной, продуктивно-творческой, научноакмепедагогической моделей).

\section{Заключение}

Эффективность и качество продуктов формирования культуры самостоятельной работы студентов техникума в модели детерминации условий эффективности современного образования определяются в следующих составных организуемого исследования:

1) использование программно-педагогического сопровождения, определяющего качество обучения в общем и частно-предметном ракурсах описания и визуализации достижений личности (использование разработанных учебных пособий и адаптивных учебных пособий, определивших высокие результаты усвоения дидактического материала, определяющего задачи развития в поле достижений и возможностей персонификации и самоактуализации деятельности в системном выборе основ и направлений продуктивного поиска и продуктивного самоутверждения через качественно решаемые задачи и противоречия);

2) использование метода проектов в решении задач акмеперсонификации качества развития личности и включенности личности обучающегося в систему социально- 
образовательных и профессионально-трудовых отношений (проекты: издательская работа в газете «ПРОФИ», проекты конкурсов «ПЕРВОКУРСНИК», «Лучший студент» и пр.);

3) выполнение курсовых работ и курсовых проектов на высоком уровне качества решения профессионально-трудовых задач (все работы имеют практическую направленность и авторски детерминированный продукт решения поставленной задачи);

4) участие в заочной Международной научно-практической конференции обучающихся «Портфолио как итог формирования культуры самостоятельной работы обучающегося» (призовые места в различных номинациях у обучающихся техникумов);

5) самопрезентации (портфолио обучающегося и профессионально-педагогические кейсы);

6) участие и победа студентов техникумов в международных, всероссийских и региональных научно-практических конференциях.

Статистические данные выделенных направлений анализа качества формирования культуры самостоятельной работы студентов техникума и системная интерпретация полученных результатов будут отражены в следующих работах.

\section{Список литературы}

1. Коновалов С.В., Бойкова И.В. Модели и механизмы формирования культуры самостоятельной работы студентов техникума // Современные наукоемкие технологии. 2018. № 6. С. 193-198.

2. Коновалов С.В., Козырева О.А. Организация продуктивной самостоятельной работы студентов как социально-профессиональная проблема // Проф. образование в России и за рубежом. 2015. № 2. С. 153-156.

3. Коновалов С.В., Козырева О.А. Педагогическое моделирование в конструктах современного образования // Вестник ТГПУ. 2017. № 1. С. 58-63.

4. Куриленко Л.В., Стрельникова В.Н. Сущность профессиональной деятельности специалистов социальной работы на современном этапе развития общества // Вестник СамГУ. 2014. № 9 (120). С. 213-216.

5. Люрья Н.А. Формирование профессиональных качеств педагога в системе образования вуза // Вестник ТГПУ. 2011. № 13. С. 151-155.

6. Меркулова Л.П., Краснощёкова Г.А. Адаптивная составляющая профессиональной мобильности // Вестник СамГУ. 2015. № 7. С. 186-190.

7. Осетрин К.Е., Пьяных Е.Г. Информационные технологии в организации самостоятельной работы студентов // Вестник ТГПУ. 2011. № 13. С. 210-213. 
8. Осетрин К.Е., Пьяных Е.Г. Методические особенности повышения квалификации учителей в области информационно-коммуникационных технологий на базе свободного программного обеспечения // Вестник ТГПУ. 2009. № 9. С. 41-43.

9. Поздеева С.И. Педагогическая деятельность как предмет психолого-педагогических исследований и публикаций // Научно-педагогическое обозрение. 2014. № 4 (6). С. 93-100.

10. Поздеева С.И. Проблемы реализации образовательной деятельности в подготовке и повышении квалификации современного педагога // Научно-педагогическое обозрение. 2014. № 3 (5). C. 64-69.

11. Руднева Т.И. Педагогическая деятельность в современном социальном контексте // Вестник СамГТУ. 2015. № 7 (129). С. 191-195.

12. Руднева Т.И., Стрекалова Н.Б. Социологическое сопровождение процесса организации самостоятельной работы студентов в условиях информатизации вузов // Социология образования. 2014. № 8. С. 4-13.

13. Свинаренко В.Г., Козырева О.А. Научное исследование по педагогике в структуре вузовского и дополнительного образования: учеб. пособ. для пед. вузов и системы ДПО. М.: НИЯУ МИФИ, 2014. 92 с.

14. Скрипко 3.А. Непрерывное развитие профессиональной компетентности преподавателя // Современное образование: содержание, технологии, качество. 2015. № 2. С. 41-43.

15. Скрипко 3.А. Организация самостоятельной работы учащихся, получающих профессии социально-гуманитарной направленности в начальном профессиональном образовании // Вестник ТГПУ. 2010. № 12. С. 178-182.

16. Торосян В.Ф., Торосян Е.С. Интерактивные технологии в формировании познавательной самостоятельности студентов // Современные проблемы науки и образования. 2016. № 6. URL: http://www.science-education.ru/ru/article/view?id=25823 (дата обращения: 07.07.2018).

17. Тютин Д.В. Применение процессного подхода в организации практики студентов среднего профессионального образования // Современные проблемы науки и образования. 2016. № 6. URL: http://www.science-education.ru/ru/article/view?id=25646 (дата обращения: 07.07.2018).

18. Царев Р.Ю., Тынченко С.В., Гриценко С.Н. Адаптивное обучение с использованием ресурсов информационно-образовательной среды // Современные проблемы науки и образования. 2016. № 5. URL: http://www.science-education.ru/ru/article/view?id=25227 (дата обращения: 07.07.2018). 
19. Шумская С.А. Организация самостоятельной работы студентов с помощью авторского электронного образовательного ресурса // Современные проблемы науки и образования. 2017. № 5. URL: http://www.science-education.ru/ru/article/view?id=26847 (дата обращения: 07.07.2018).

20. Щербакова Е.Е., Мухина Т.Г., Плешков А.В. Фрейм-технология как условие развития креативности студентов // Современные проблемы науки и образования. 2016. № 6. URL: http://www.science-education.ru/ru/article/view?id=25591 (дата обращения: 07.07.2018). 